\title{
Chaotic theory incorporated with PSO algorithm for solving optimal reactive power dispatch problem of power system
}

\author{
Shaima Hamdan Shri, Ayad Fadhil Mijbas \\ Department of Electrical Techniques, Technical Institute-Suwaira, Middle Technical University, Iraq
}

\begin{tabular}{l} 
Article Info \\
\hline Article history: \\
Received Oct 25, 2020 \\
Revised May 3, 2021 \\
Accepted May 19, 2021 \\
\hline
\end{tabular}

\section{Keywords:}

CPSO

Optimal reactive power dispatch

$P_{\text {LosS }}$

PSO

\begin{abstract}
In this paper, the chaotic particle swarm optimization (CPSO) algorithm is combined with MATPOWER toolbox and used as an optimization tool for attaining solving the optimal reactive power dispatch (RPD) problem, by finding the optimal adjustment of reactive power control variables like a voltage of generator buses (VG), capacitor banks (QC) and transformer taps (Tap) while satisfying some of equality and inequality constraints at the same time. CPSO and Simple PSO algorithms will be checked in a large system such as IEEE node -118. CPSO and Simple PSO algorithms have been implemented and simulated in the MATLAB program, version (R2013b/mfile). Then compassion these results with the results obtained in the other algorithms in the literature like the comprehensive learning particle swarm optimization (CLPSO) algorithm. The simulation results confirm that the CPSO algorithm has high efficiency and ability in terms of decrease real power losses $\left(P_{\text {LosS }}\right)$, and improve voltage profile compared with the obtained by using the simple (PSO) algorithm and (CLPSO) at light load.
\end{abstract}

This is an open access article under the CC BY-SA license.

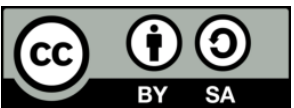

Corresponding Author:

Shaima Hamdan Shri

Department of Electrical Techniques

Technical Institute-Suwaira

Middle Technical University, Iraq

Email: shaima123@mtu.edu.iq

\section{INTRODUCTION}

Optimal reactive power dispatch (RPD) problem is considered as a complex, non-continous problem. The power system involves of generation, transmission and distribution system to provide the electric power to the consumers. It is an essential modern problem in the power system operating and control. The objective of (RPD) problem is to find the best value of reactive power independent (control) variables so as to minimize a certain objective function such as power loss and voltage deviation. The main goals in this work are to get minimum power loss, and enhance voltage profile for the system and this goals can be achieved through an optimal alteration of the reactive power control variables like, generator voltages value $\left(\mathrm{V}_{\mathrm{G}}\right)$, the amount of (VAR) that injected from the capacitor banks $\left(\mathrm{Q}_{\mathrm{C}}\right)$ and transformer taps (Tap) settings while dealing with equality and inequality constrains at the same time [1]. The electrical loads are not constant and vary from hour to hour. Any varying in power demands can lead to higher or lower voltages in the system, so it must keep the reactive power devices like (viz. $\mathrm{V}_{\mathrm{G}}$, Tap and $\mathrm{Q}_{\mathrm{C}}$ ) varying simultaneously with the changing in the electric load and voltage [2]. Undeniably, over the last decades, RPD problem plays a vital role in the power system operation and control and has recorded an ever-intense interest of the authors because of remarkable and great effect on the economic, safe and security operation problem.

This problem is considered as a branch problem of the optimal power flow (OPF) calculation. Carpentier was the first to introduce the model and concept of (OPF) in the early 1960s [3]. Then, many 
researchers has been working on solving OPF problem by utilizing multi methods and like ant lion optimizer (ALO) and integration of the invasive weed optimization (IWO) and Powell's pattern search (PPS) method [4], [5]. Ariantara et al. Using differential evolution (DE) Algorithm for the solution of OPF [6].

In the past, researchers were presented a lot of researches on (RPD) problem, and presented a number of optimization algorithms. These algorithms are classified into two types: conventional optimization algorithms and computational optimization algorithms. The concept of conventional algorithm is beginning from an initial point. These algorithms contain interior point methods (IPM) [7], linear programing (LP) [8], non-linear programming [9] and dynamic programming (DP) [10]. These algorithms have several disadvantages such as unable to dealing with complex optimization problem, unable to dealing with problem that include very large number of variables, huge calculations, big implementation time and convergence to the nearby local optima. So, it becomes essential for finding and developing methods able to avoid these disadvantages.

So, several optimization techniques have been presented in order to avoid these disadvantages of the conventional optimization algorithms and these algorithms called computational optimization algorithms and the basic concept of these algorithms are beginning from an initial solution swarm like, genetic algorithm (GA) [11], gentoo penguin algorithm (GPA) [12], hybrid GA-IPM [13], meleagris gallopavo algorithm (MGA) [14], chaotic predator-prey brain storm optimization (CPB) algorithm [15], Gravitational search algorithm (GSA) and sine cosine algorithm (SCA) [16], enhanced fruit fly optimization algorithm (EFF) and status of material algorithm (SMA) [17] and polar wolf optimization (PWO) algorithm [18] and particle swarm optimization (PSO) [19], have been presented for the solution of RPD problem in the literature. From all these algorithms, PSO shown great reliability to overcome the drawbacks of the conventional algorithms and can easily be applied to multi problems, but it doesn't mean that PSO algorithm doesn't involve any disadvantages. Therefore, in solving the non-continuous and complex problems this algorithm is declining to the local minima at the premature convergence, on the other hand, also it depends on its parameter settings.

So, many researchers working for enhance PSO algorithm and prevent that disadvantages by using sundry methods and techniques compact with PSO algorithm. Zhang et al. have proposed a two-phase HPSO technique to solved the RPD problem [20]. Vlachogiannis et al. have applied (PSO, GPAC-PSO, and LPACPSO) algorithms for reactive power and voltage control [21].

In the presented work, simple PSO has been developed to solve the RPD problem for minimizing power losses and voltage profile enhancement. So as to enhance the searching quality of the simple PSO algorithm and to avoid falling into the local minima and to decrease the calculation time, Chaotic PSO (CPSO) is utilized so as to overcome these disadvantages. The chaos greatly helps the CPSO algorithm for slip more easily from the local minima because of the special behavior, and strong ability for the chaotic theory. Simple PSO and CPSO are applied for solving the RPD problem on IEEE Node-118 system, then the simulation results were compared with other algorithm in the literature, like comprehensive learning particle swarm optimization (CLPSO).

\section{PROBLEM FORMULATION}

In this section, the main goal in this study is to find the best combinations of reactive power independent variables so as to decrease the power losses $\left(\mathrm{P}_{\text {Loss }}\right)$ for the system while dealing with numbers of equality and inequality constrains at the same time. So, the objective function in this work can be expressed as shown in (1) [22], [23].

$$
\operatorname{Min} \mathrm{P}_{\mathrm{Loss}}=\sum_{\mathrm{K}=1}^{\mathrm{Ntl}} \mathrm{G}_{\mathrm{K}}\left(\mathrm{V}_{\mathrm{i}}^{2}+\mathrm{V}_{\mathrm{j}}^{2}-2 \mathrm{~V}_{\mathrm{i}} \mathrm{V}_{\mathrm{i}} \cos \left(\phi_{\mathrm{i}}-\phi_{\mathrm{j}}\right)\right.
$$

where, $P_{\text {Loss }}$ is the active power loss function. Ntl depict the number of branches. $G_{K}$ is the conductance of branch $\mathrm{K} . \mathrm{V}_{\mathrm{i}}, \mathrm{V}_{\mathrm{j}}$ are the voltage magnitudes at node $\mathrm{i}$ and $\mathrm{j} . \phi_{\mathrm{i}}, \phi_{\mathrm{j}}$ are the difference angles voltage at node $\mathrm{i}$ and $\mathrm{j}$. ( $\mathrm{i}$ and $\mathrm{j}$ ) are the sending and receiving nodes of branch $\mathrm{K}$.

\subsection{System constrains}

Equality constrains are the load flow equation and defined [24]:

$$
\left\{\begin{array}{c}
\mathrm{P}_{\mathrm{Gi}}-\mathrm{P}_{\mathrm{Di}}-\mathrm{V}_{\mathrm{i}} \sum_{\mathrm{j}=1}^{\mathrm{NB}} \mathrm{V}_{\mathrm{j}}\left(\mathrm{G}_{\mathrm{ij}} \cos \left(\phi_{\mathrm{ij}}\right)+\mathrm{B}_{\mathrm{ij}} \sin \left(\phi_{\mathrm{ij}}\right)\right)=0 \\
\mathrm{Q}_{\mathrm{Gi}}-\mathrm{Q}_{\mathrm{Di}}-\mathrm{V}_{\mathrm{i}} \sum_{\mathrm{j}=1}^{\mathrm{NB}} \mathrm{V}_{\mathrm{j}}\left(\mathrm{G}_{\mathrm{ij}} \sin \left(\phi_{\mathrm{ij}}\right)-\mathrm{B}_{\mathrm{ij}} \cos \left(\phi_{\mathrm{ij}}\right)\right)=0
\end{array}\right.
$$


where $\mathrm{P}_{\mathrm{Gi}}, \mathrm{Q}_{\mathrm{Gi}}$ are the real $(\mathrm{MW})$ and reactive power (VAR) output from the generators at node i. $\mathrm{P}_{\mathrm{Di}}, \mathrm{Q}_{\mathrm{Di}}$ are the real (MW) and reactive power (VAR) load demand at node $\mathrm{i} . \mathrm{G}_{\mathrm{ij}}, \mathrm{B}_{\mathrm{ij}}$ are the mutual and susceptance conductance among $\mathrm{i}$ node and $\mathrm{j}$ node. $\phi_{\mathrm{ij}}$ depict the voltage angle magnitude in node $\mathrm{i}$ and $\mathrm{j}$. Inequality constrains involves independent (control) variables like, generator voltages $\left(\mathrm{V}_{\mathrm{G}}\right)$, injected reactive power from capacitor $\left(\mathrm{Q}_{\mathrm{C}}\right)$ and transformer positions (Tap) [25]:

$$
\left\{\begin{array}{c}
\mathrm{V}_{\mathrm{Gi}}^{\min } \leq \mathrm{V}_{\mathrm{Gi}} \leq \mathrm{V}_{\mathrm{Gi}}^{\max }, \mathrm{i} \in \mathrm{N}_{\mathrm{G}} \\
\operatorname{Tap}_{\mathrm{K}}^{\min } \leq \operatorname{Tap}_{\mathrm{K}} \leq \operatorname{Tap}_{\mathrm{K}}^{\max }, \mathrm{K} \in \mathrm{N}_{\mathrm{T}} \\
\mathrm{Q}_{\mathrm{Ci}}^{\min } \leq \mathrm{Q}_{\mathrm{Ci}} \leq \mathrm{Q}_{\mathrm{Ci}} \max ^{\text {max }}, \mathrm{i} \in \mathrm{N}_{\mathrm{C}}
\end{array}\right.
$$

where $\mathrm{N}_{\mathrm{G}}$ depict the number of generator nodes. $\mathrm{V}_{\mathrm{Gi}}{ }^{\min }, \mathrm{V}_{\mathrm{Gi}}$ max are the Minimum limit and maximum limit of generator voltage magnitude at $\mathrm{i}$-node. $\mathrm{N}_{\mathrm{T}}$ depict the total number of transformers. $\mathrm{Tap}_{\mathrm{k}}{ }^{\min }, \mathrm{Tap}_{\mathrm{k}}{ }^{\max }$ are the Minimum limit and Maximum limit of transformer ratio at branch $\mathrm{K} . \mathrm{N}_{\mathrm{C}}$ depict the total number of injected VAR source. $Q_{C i}{ }^{\min }, Q_{C i}{ }^{\max }$ : are the Minimum limit and Maximum limit of injected VAR source from shunt capacitor at node i. And also involves dependent (state) variables such as voltage at load bus $\left(V_{l}\right)$ and reactive power output from the generators $\left(Q_{G}\right)$ [25]:

$$
\left\{\begin{array}{l}
Q_{G i}{ }^{\min } \leq Q_{G i} \leq Q_{G i}{ }^{\max }, i \in N_{G} \\
V_{l i}{ }^{\text {min }} \leq V_{\mathrm{li}} \leq V_{\mathrm{li}}{ }^{\text {max }}, \mathrm{i} \in \mathrm{N}_{\mathrm{PQ}}
\end{array}\right.
$$

where, $\mathrm{N}_{\mathrm{G}}$ depict the number of generator nodes. $\mathrm{Q}_{\mathrm{Gi}}{ }^{\mathrm{min}}, \mathrm{Q}_{\mathrm{Gi}}{ }^{\max }$ are the minimum (lower) limit and maximum (upper) limit of reactive power output of generator at $\mathrm{i}$ - node. $\mathrm{N}_{\mathrm{PQ}}$ depict the number of load nodes. $\mathrm{V}_{\mathrm{li}}$ min, $\mathrm{V}_{\mathrm{li}}{ }^{\max }$ : are the Minimum (lower) limit and Maximum (upper) limit of voltage magnitude at i-node.

\subsection{The generalized objective function}

In this problem, the dependent variables can be added to (1) by utilizing penalty factors to constrain, so (1) can be written as shown in (5) [25]:

$$
\operatorname{Min} F=\mathrm{P}_{\mathrm{Loss}}+\lambda_{\mathrm{V}} \sum_{\mathrm{i}=1}^{\mathrm{NL}}\left(\mathrm{v}_{\mathrm{Li}}-\mathrm{v}_{\mathrm{Li}}^{\lim }\right)^{2}+\lambda_{\mathrm{Q}} \sum_{\mathrm{i}=1}^{\mathrm{NG}}\left(\mathrm{Q}_{\mathrm{Gi}}-\mathrm{Q}_{\mathrm{Gi}}{ }^{\lim }\right)^{2}
$$

where $\lambda_{V}$ and $\lambda_{Q}$ are penalty terms; $X^{\mathrm{lim}}$ is the limit value of inequality constrains; $N L$ is the total number of load nodes; $N G$ is the numbers of generation station and $\mathrm{P}_{\text {Loss }}$ is given in (1).

\subsection{Concept of average voltage}

In this study, the new average voltage index is suggested to deal with all voltage nodes as well as satisfy most of the electrical utility limits. The equation of this concept can be written as shown in (6):

$$
\mathrm{V}_{\mathrm{av}}=\frac{\sum_{\mathrm{i}=1}^{\mathrm{Nn}} \mathrm{V}_{\mathrm{i}}}{\mathrm{N}_{\mathrm{n}}}
$$

where $V_{a v}$ depict the average voltage of all system; $V_{i}$ depict the voltage in node $i . N_{n}$ depict the total number of nodes.

\section{OPTIMIZATION PROCESS}

\subsection{Simple PSO algorithm}

PSO algorithm is a best type for artificial intelligence, which mimics the social behavior of the animals which does not have any leader when searching for food like, bird flocking and fish schooling. It has several advantages such as simple, fast, can applied for solving optimization problem and guarantees best solution within lesser calculation time and the convergence characteristic have very stable than other stochastic algorithms and capable of dealing with continuous and discrete variables and does not have mutation and crossover operation like genetic algorithm. An individual represents the probable solution and every group of individuals represents a swarm. This theory was first put forward in 1995 [26]. Each individual has best position discover by the individual it self and it is stored in a memory called local best position $\left(\mathrm{P}_{\text {best }}\right)$, and the best position discovered among all individuals $\left(\mathrm{P}_{\text {best }}\right)$ in the swarm also stored in a memory called global best position $\left(G_{\text {best }}\right)$, at every step the location of $P_{\text {best }}$ and $G_{\text {best }}$ are changing. Then, 
the velocity and position of every individual in the swarm are changed by employing the calculation of the present individual velocity and the location from $P_{\text {best }}$ position and $G_{\text {best }}$ position. The velocity and distance from $P_{\text {best }}$ location and $G_{\text {best }}$ location of the agents will be changed by utilizing (7) and (8) [27].

$$
\begin{aligned}
& \mathrm{V}_{\mathrm{i}}^{\mathrm{k}+1}=\mathrm{K}^{*}\left[\mathrm{~W}_{\mathrm{PSO}} * \mathrm{~V}_{\mathrm{i}}^{\mathrm{k}}+\mathrm{C}_{1} * \mathrm{R}_{1} *\left(\mathrm{P}_{\text {best }(\mathrm{i})}^{\mathrm{k}}-\mathrm{X}_{\mathrm{i}}^{\mathrm{k}}\right)+\mathrm{C}_{2} * \mathrm{R}_{2} *\left(\mathrm{G}_{\text {best }(\mathrm{i})}^{\mathrm{k}}-\mathrm{X}_{\mathrm{i}}^{\mathrm{k}}\right)\right] \\
& \mathrm{X}_{\mathrm{i}}^{\mathrm{k}+1}=\mathrm{X}_{\mathrm{i}}^{\mathrm{k}}+\mathrm{V}_{\mathrm{i}}^{\mathrm{k}+1}
\end{aligned}
$$

where, $W_{P S O}$ is the inertia coefficient of PSO technique. $V_{i}$ represents the velocity of individual. $C_{1}, C_{2}$ are the two learning factors that utilized to pull each agent to $P_{\text {best }}$ location and $G_{\text {best }}$ location within range [0 to 2.05]. $R_{1}, R_{2}$ are the two random numbers within limit [0 to 1]. $P_{\text {best (i) }}$ depicts the local best position. $G_{\text {best }(i)}$ represents the global best position. $X_{i}$ represents the position of the individual and $K$ is the constriction factor and it is utilize to improve the performance of the simple PSO algorithm and it was introduced by Shi indicate that using of this factor may be necessary and can be expressed [28].

$$
\mathrm{K}=\frac{2}{\left|2-\phi-\sqrt{\phi^{2}-4 \phi}\right|}, \phi=\mathrm{C}_{1}+\mathrm{C}_{2}, \phi \geq 4
$$

A proper choice of the inertia weight $(W)$ can achieve a balance between global location and local location. So, in this work, $W_{P S O}$ was reduced linearly from (0.4-0.9) for each iteration (step) to search in a big area at the start of the simulation and to attains balance between global position $\left(G_{b e s t}\right)$ and local position $\left(P_{\text {best }}\right)[28]$ :

$$
\mathrm{W}_{\mathrm{PSO}}=\mathrm{W}_{\max }-\left(\frac{\mathrm{W}_{\max }-\mathrm{W}_{\min }}{\max _{\text {iteration }}}\right) * \text { iter }
$$

where $W_{\max }$ is the max (upper) value of weight. $W_{\min }$ is the min (lower) value of weight. iter is the current iteration and max $_{\text {iteration }}$ is the max (upper) iteration.

\subsection{CPSO algorithm}

Despite the advantages of the simple PSO algorithm, but it has several limitations such as highly depend on its parameter and decline to the local optimal at the premature convergence especially when the problem is very complex.In this work, so as to prevent these limitations and to boost the quality and performance, and the searching ability of the simple PSO algorithm, chaotic theory with Simple PSO are merged to form a hybrid algorithm called the CPSO algorithm. and undeniably, this merge is a very helpful to slip from the local optimal because of the special behavior and great ability of the chaotic CPSO algorithm [29]. In this work, the logistic map equation of the hybrid CPSO algorithm was described by the (11) [30].

$$
\beta^{\mathrm{k}+1}=\mu \beta^{\mathrm{k}}\left(\left(1-\beta^{\mathrm{k}}\right)\right), 0 \leq \beta^{1} \leq 1
$$

Where, $\mathrm{k}$ is the number of the iteration (steps), and the control parameter $\mu$ was set within a range (0.0 to 4.0). The magnitude of $\mu$ decides whether $\beta$ stabilizes at a constant area, oscillates within restricted limits, or behaves chaotically in an unpredictable form. And (11) was shows chaotic dynamics when $\mu=4.0$ and $\beta^{\wedge} 1$ $\in\{0,0.25,0.5,0.75,1\}$, it shows the sensitive depend on its initial conditions, which is the basic features of chaotic. The new inertia weight factor $\left(\mathrm{W}_{\mathrm{CPSO}}\right)$ was calculated by multiplying the ( $\left.\mathrm{W}_{\mathrm{PSO}}\right)$ for (10) and logistic map for (11) to form (12).

$$
\mathrm{W}_{\mathrm{CPSO}}=\mathrm{W}_{\mathrm{PSO}} * \beta^{\mathrm{k}+1}
$$

To enhance the behavior of the simple PSO, this work presents a novel velocity update by blending inertia weight factor WPSO with the logistic map equation $(\beta)$. Finally, by blending (12) with (7), the following velocity changed equation to the proposed CPSO algorithm was obtained:

$$
\mathrm{V}_{\mathrm{i}}^{\mathrm{k}+1}=\mathrm{W}_{\text {CPSO }} * \mathrm{~V}_{\mathrm{i}}^{\mathrm{k}}+\mathrm{C}_{1} * \mathrm{R}_{1} *\left(\mathrm{P}_{\text {best }(\mathrm{i})}^{\mathrm{k}}-\mathrm{X}_{\mathrm{i}}^{\mathrm{k}}\right)+\mathrm{C}_{2} * \mathrm{R}_{2} *\left(\mathrm{G}_{\text {best }(\mathrm{i})}^{\mathrm{k}}-\mathrm{X}_{\mathrm{i}}^{\mathrm{k}}\right)
$$

In the CPSO algorithm, $\mathrm{W}_{\text {CPSO }}$ was oscillates and decrease simultaneously from (0.9-0.4) for total iteration, but in traditional PSO was decrease linearly. Table 1 shows a final choice of the control parameters CPSO and simple PSO algorithms that is considered the optimal choice in this study. 
Table 1. Parameters used for CPSO and PSO algorithms

\begin{tabular}{lll}
\hline Parameters of CPSO and PSO algorithms & CPSO & PSO \\
\hline
\end{tabular}

\begin{tabular}{ccc}
$\mathrm{n}$ & 100 & 100 \\
$\mathrm{c}_{1}$ & 2 & 2 \\
$\mathrm{c}_{2}$ & 2 & 2 \\
$\mathrm{r}_{1}$ & 1 & 1 \\
$\mathrm{r}_{2}$ & 1 & 1 \\
$\mathrm{w}_{\max }$ & 0.9 & 0.9 \\
$\mathrm{w}_{\min }$ & 0.4 & 0.4 \\
$\mu$ & 4 & - \\
$\mathrm{B}^{1}$ & 0.75 & - \\
$\max _{\text {iter }}$ & 300 & 300 \\
numbers of particles & 100 & 100 \\
\hline
\end{tabular}

\section{CASE STUDY AND SIMULATION RESULTS}

To verify and test the performance and ability for the proposed methods (i.e. simple PSO and CPSO) for solving RPD problem in a complex power system, IEEE node-118 systems is employed. This system is involve, 12 injected reactive power sources $\left(Q_{C}\right)$ from shunt capacitors, 186 branches, 54 generator voltages $\left(\mathrm{V}_{\mathrm{G}}\right)$ and 9 transformer tap ratios (Tap) at branches 8, 32, 36, 51, 93, 95, 102, 107 and 127, the limits of these variables are illustrated in Table 2. Branch, bus, generator, the upper and lower limits of the reactive power in Mvar for the generators and other operating data are given in [31]. So, this system has 75 control (independent) variables as displayed given in Table 3 (see appendix), and at base case the initial active and reactive power generations are $P_{G}=4374.86 \mathrm{Mw}$ and $Q_{G}=795.68 \mathrm{Mvar}$, the initial active and reactive power loads are $P_{\text {Load }}=4242.00 \mathrm{Mw}$ and $Q_{\text {Load }}=1438.00 \mathrm{Mvar}$, the initial active and reactive power losses are $P_{\text {Loss }}=132.86 \mathrm{Mw}$ and $Q_{\text {Loss }}=783.69 \mathrm{Mvar}$ and they are 3 voltages outside the limits in the base placed at bus 53, 76 and 118 and the value of these voltages in p.u are $V_{53}=0.946, V_{76}=0.943$ and $V_{118}=0.949$. The simulation results are given in Table 3 (see appendix) for the goal of minimization of $P_{\text {Loss }}$ for the system and according to these results, found the results that yielded from the CPSO algorithm are the best for solving large power system compared to the results that obtained in the simple PSO and other algorithms in the literature like comprehensive learning particle swarm optimization CLPSO [32] algorithms. Figure 1 shows the comparison among the percentage reduction of power losses for the used algorithms, and Figure 2 shows the comparison among the real power loss value $\left(P_{\text {Loss }}\right)$ for the used algorithms. The convergence characteristics of $P_{\text {Loss }}$ in MW for the simple PSO and CPSO algorithms are expose in Figures 3 and 4, and from these figures, it can be seen that CPSO algorithm performs best and reaching to the global solution in less time than simple PSO for the solution of RPD problem. The voltage profile are given in Figure 5 and from this figure it is clear that the voltage average at initial is about $\mathbf{0 . 9 8 6}$, at PSO is about 1.024 , and at CPSO is about 1.045 and also all buses voltages are inside the limits after CPSO algorithm but in the simple PSO algorithm $V_{32}$ and $V_{33}$ are still outside the limits. The power loss reduction $\left(P_{\text {Loss }}\right)$ is $15.1 \%$ (from $132.8 \mathrm{Mw}$ to $112.65 \mathrm{Mw}$ ) achieved by utilizing CPSO algorithm, which is consider the largest reduction in $\mathrm{P}_{\mathrm{L}}$ than that accomplished in the simple PSO, CLPSO [32] algorithms.

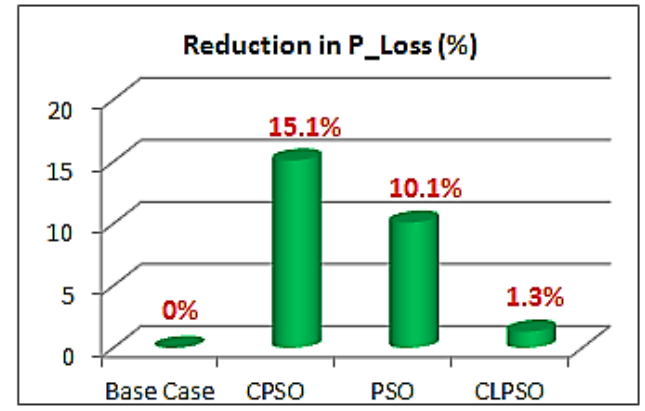

Figure 1. Real power loss reduction in percentage

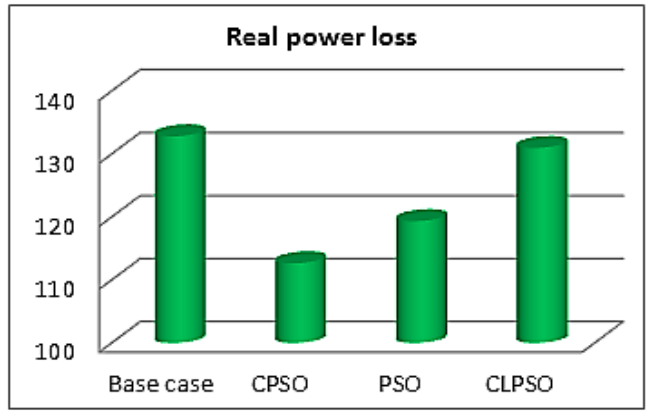

Figure 2. Comparison of real power loss $\left(P_{\text {Loss }}\right)$

Table 2. Control variables limits

\begin{tabular}{clcc}
\hline System Type & \multicolumn{1}{c}{ Variables } & Min & Max \\
\hline 118 Bus & Generator voltage $\left(V_{G}\right)$ & 0.95 & 1.1 \\
& Transformer position $($ Tap $)$ & 0.9 & 1.1 \\
& VAR source compensation $\left(Q_{C}\right)$ & 0 & 0.20 \\
\hline
\end{tabular}




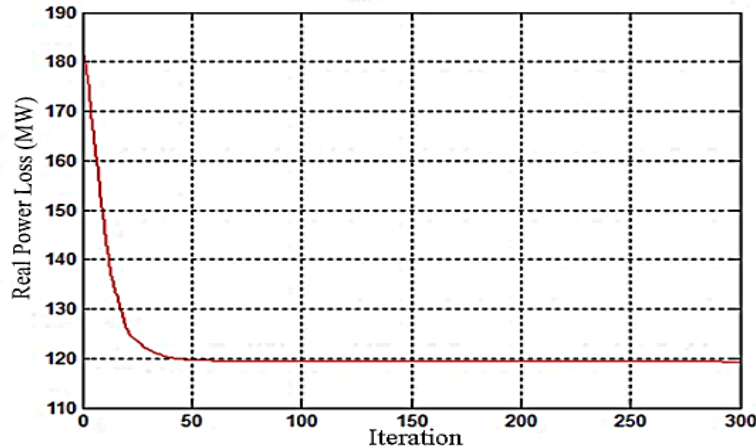

Figure 3. Convergence for IEEE 118 node power system with simple PSO algorithm

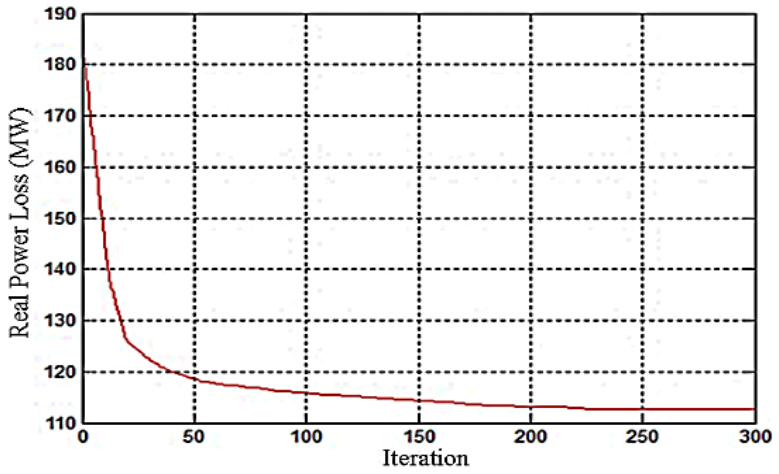

Figure 4. Convergence for IEEE 118 node power system with CPSO algorithm

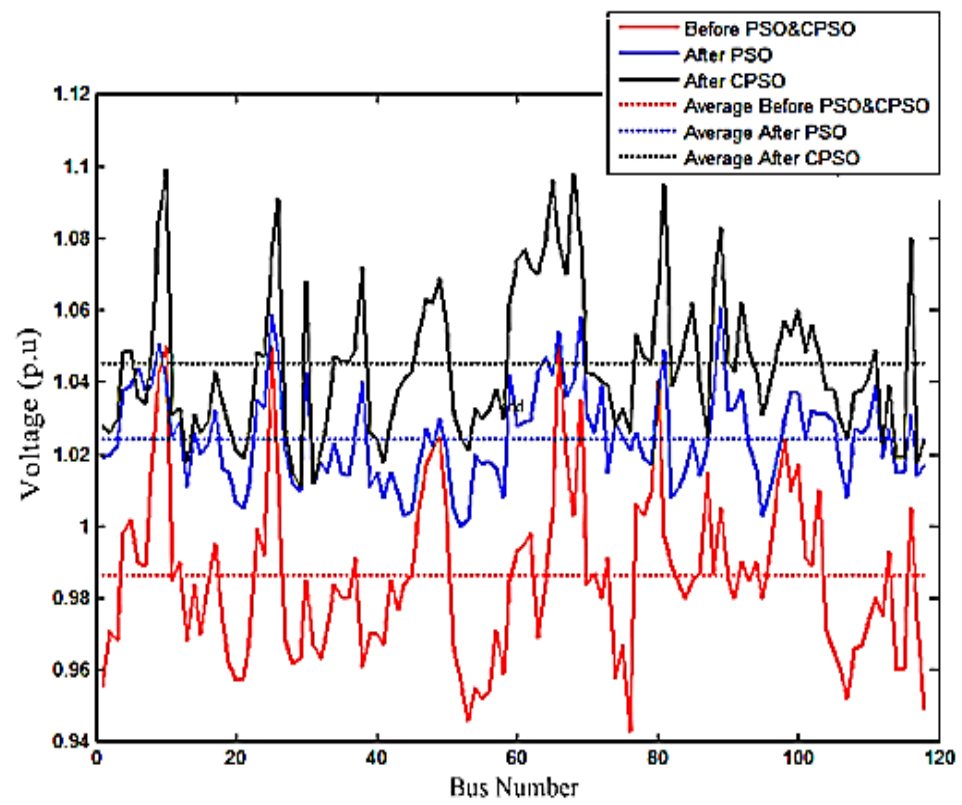

Figure 5. Voltage profile of IEEE 118-node system

\section{CONCLUSIONS}

In this study, two types of algorithms are utilized they simple PSO and CPSO. The chaotic particle swarm optimization algorithm is combined with MATPOWER toolbox and used as an optimization tool for attaining solving the optimal reactive power dispatch problem. The objective function has been utilized to decrease power loss in the power system branches and improve voltage profile. The efficiency and high quality of CPSO algorithm have been proved by examining on IEEE Node-118 system. CPSO provided the best technique to search for an optimal solution that decreased the calculation time and has high speed convergence in both power loss minimization and voltage profile improvement compared with the results obtained from using simple PSO and other results reported in the literature like comprehensive learning particle swarm optimization algorithm. Where, a percentage reduction in power loss be (15.1\%) for CPSO, (10.1\%) for PSO, and (1.3\%) for CLPSO.

\section{SUGGESTIONS FOR FUTURE WORK}

In the future, the research can be developed by optimizing total voltage deviation (TVD) and voltage stability index (VSI) separately as a single objective function or as multi-objective functions in order to achieve more improvement in the RPC problem. 


\section{APPENDIX}

Table 3. Simulation result of IEEE- 118 node systems

\begin{tabular}{|c|c|c|c|c|}
\hline Control Variables & Base Case & CPSO & $\mathrm{PSO}$ & CLPSO [32] \\
\hline$V_{G} 1$ & 0.955 & 1.028 & 1.019 & 1.033 \\
\hline$V_{G} 4$ & 0.998 & 1.048 & 1.038 & 1.055 \\
\hline$V_{G} 6$ & 0.990 & 1.036 & 1.044 & 0.975 \\
\hline$V_{G} 8$ & 1.015 & 1.047 & 1.039 & 0.966 \\
\hline$V_{G} 10$ & 1.050 & 1.099 & 1.040 & 0.981 \\
\hline$V_{G} 12$ & 0.990 & 1.033 & 1.029 & 1.009 \\
\hline$V_{G} 15$ & 0.970 & 1.026 & 1.020 & 0.978 \\
\hline$V_{G} 18$ & 0.973 & 1.034 & 1.016 & 1.079 \\
\hline$V_{G} 19$ & 0.962 & 1.028 & 1.015 & 1.080 \\
\hline$V_{G} 24$ & 0.992 & 1.047 & 1.033 & 1.028 \\
\hline$V_{G} 25$ & 1.050 & 1.075 & 1.059 & 1.030 \\
\hline$V_{G} 26$ & 1.015 & 1.091 & 1.049 & 0.987 \\
\hline$V_{G} 27$ & 0.968 & 1.027 & 1.021 & 1.015 \\
\hline$V_{G} 31$ & 0.967 & 1.012 & 1.012 & 0.961 \\
\hline$V_{G} 32$ & 0.963 & 1.021 & 1.018 & 0.985 \\
\hline$V_{G} 34$ & 0.984 & 1.047 & 1.023 & 1.015 \\
\hline$V_{G} 36$ & 0.980 & 1.046 & 1.014 & 1.084 \\
\hline$V_{G} 40$ & 0.970 & 1.024 & 1.015 & 0.983 \\
\hline$V_{G} 42$ & 0.985 & 1.029 & 1.015 & 1.051 \\
\hline$V_{G} 46$ & 1.005 & 1.054 & 1.017 & 0.975 \\
\hline$V_{G} 49$ & 1.025 & 1.069 & 1.030 & 0.983 \\
\hline$V_{G} 54$ & 0.955 & 1.033 & 1.020 & 0.963 \\
\hline$V_{G} 55$ & 0.952 & 1.030 & 1.017 & 0.971 \\
\hline$V_{G} 56$ & 0.954 & 1.032 & 1.018 & 1.025 \\
\hline$V_{G} 59$ & 0.985 & 1.062 & 1.042 & 1.000 \\
\hline$V_{G} 61$ & 0.995 & 1.077 & 1.029 & 1.077 \\
\hline$V_{G} 62$ & 0.998 & 1.072 & 1.029 & 1.048 \\
\hline$V_{G} 65$ & 1.005 & 1.096 & 1.042 & 0.968 \\
\hline$V_{G} 66$ & 1.050 & 1.051 & 1.054 & 0.964 \\
\hline$V_{G} 69$ & 1.035 & 1.078 & 1.058 & 0.957 \\
\hline$V_{G} 70$ & 0.984 & 1.043 & 1.031 & 0.976 \\
\hline$V_{G} 72$ & 0.980 & 1.040 & 1.039 & 1.024 \\
\hline$V_{G} 73$ & 0.991 & 1.039 & 1.015 & 0.965 \\
\hline$V_{G} 74$ & 0.958 & 1.028 & 1.029 & 1.073 \\
\hline$V_{G} 76$ & 0.943 & 1.026 & 1.021 & 1.030 \\
\hline$V_{G} 77$ & 1.006 & 1.053 & 1.026 & 1.027 \\
\hline$V_{G} 80$ & 1.040 & 1.067 & 1.038 & 0.985 \\
\hline$V_{G} 85$ & 0.985 & 1.062 & 1.024 & 0.983 \\
\hline$V_{G} 87$ & 1.015 & 1.025 & 1.022 & 1.088 \\
\hline$V_{G} 89$ & 1.000 & 1.083 & 1.061 & 0.989 \\
\hline$V_{G} 107$ & 0.952 & 1.024 & 1.008 & 0.976 \\
\hline$V_{G} 110$ & 0.973 & 1.041 & 1.028 & 1.041 \\
\hline$V_{G} 111$ & 0.980 & 1.049 & 1.039 & 0.979 \\
\hline$V_{G} 112$ & 0.975 & 1.023 & 1.019 & 0.976 \\
\hline$V_{G} 113$ & 0.993 & 1.039 & 1.027 & 0.972 \\
\hline$V_{G} 116$ & 1.005 & 1.080 & 1.031 & 1.033 \\
\hline$Q_{C} 48$ & 0.150 & 0.047 & 0.056 & 0.028 \\
\hline$Q_{C} 74$ & 0.120 & 0.112 & 0.120 & 0.005 \\
\hline$Q_{C} 79$ & 0.200 & 0.150 & 0.140 & 0.148 \\
\hline$Q_{C} 82$ & 0.200 & 0.190 & 0.180 & 0.194 \\
\hline$Q_{C} 83$ & 0.100 & 0.163 & 0.166 & 0.069 \\
\hline$Q_{C} 105$ & 0.200 & 0.026 & 0.190 & 0.090 \\
\hline$Q_{C} 107$ & 0.060 & 0.077 & 0.129 & 0.049 \\
\hline$Q_{C} 110$ & 0.060 & 0.137 & 0.014 & 0.022 \\
\hline$P_{G}(\mathrm{MW})$ & 4374.8 & 4354.7 & 4361.4 & $\mathrm{NR}^{*}$ \\
\hline$Q_{G}$ (Mvar) & 795.68 & 535.56 & 653.58 & $\mathrm{NR}^{*}$ \\
\hline Reduction in $\mathrm{P}_{\text {Loss }}(\%)$ & 0 & 15.1 & 10.1 & 1.3 \\
\hline (Mw) Total $\mathrm{P}_{\mathrm{L}}$ & 132.8 & 112.65 & 119.34 & 130.96 \\
\hline
\end{tabular}

NR*: means that the value was not reported.

\section{ACKNOWLEDGEMENTS}

The authors would like to acknowledge the Electrical Techniques Department, Al Suwaira Technical Institute, Middle Technical University for their encouragement and support. 


\section{REFERENCES}

[1] H. Khazali, et al., "Optimal reactive power dispatch based on harmony search algorithm," International Journal of Electrical Power \& Energy Systems, vol. 33, pp. 684-692, 2011, doi: 10.1016/j.ijepes.2010.11.018.

[2] K. R. C. Mamandur, et al., "Optimal control of reactive power flow for improvements in voltage profilesand for real power loss minimization," IEEE Trans Power Apparat Syst, vol. PAS-100, pp. 3185-3194, 1981, doi: 10.1109/TPAS.1981.316646.

[3] X. He, et al., "Fuzzy Multiobjective Optimal Power Flow Based on Modified Artificial Bee Colony Algorithm," Mathematical Problems in Engineering, vol. 2014, pp. 1-12, 2014, doi: 10.1155/2014/961069.

[4] R. Kouadri, et al., "Optimal Power Flow Solution for Wind Integrated Power in presence of VSC-HVDC Using Ant Lion Optimization," Indonesian Journal of Electrical Engineering and Computer Science (IJEECS), vol .12, no. 2, pp. 625-633, 2018, doi: 10.11591/ijeecs.v12.i2.pp625-633.

[5] M. Kaur, et al., "An integrated optimization technique for optimal power flow solution," Soft Computing, vol. 24, pp. 10865-10882, 2020, doi: 10.1007/s00500-019-04590-3.

[6] H. Ariantara, et al., "The Solution for optimal power flow (OPF) Method Using Differential Evolution Algorithm," IJITEE (International Journal of Information Technology and Electrical Engineering), vol .1, no. 1, pp. 19-24, 2017, doi: 10.22146/ijitee.25141.

[7] S. Granville, et al., "Optimal reactive dispatch through interior point methods," IEEE Trans. Power Syst., vol. 9 , no. 1, pp. 136-146, Feb. 1994, doi: 10.1109/59.317548.

[8] R. Hooshmand, et al., "Application of artificial neural networks in controlling voltage and reactive power," Scientia Iranica, vol. 12, no. 1, pp. 99-108, 2005.

[9] D. Pudjianto, et al., "Allocation of VAR support using LP and NLP based optimal power flows," IEE Proc. Gen. Trans. Dist., vol. 149, no. 4, 2002, pp. 377-383, doi: 10.1049/ip-gtd:20020200.

[10] F.C. Lu, et al., "Reactive power/voltage control in a distribution substation using dynamic programming," IEEE Proc. Gen. Trans. Distrib. vol. 142, 1995, pp. 639-645, doi: 10.1049/ip-gtd:19952210.

[11] Ghasempour, et al., "A new genetic based algorithm for channel assignment problem," Computational Intelligence, Theory and Applications, Ed. B. Reusch, Berlin: Springer, pp. 85-91, 2006, doi: 10.1007/3-540-34783-6_10.

[12] K. Lenin, "Diminution of real power loss by novel gentoo penguin algorithm," International Journal of Informatics and Communication Technology (IJ-ICT), vol. 9, no. 3, pp. 150-156, 2020, doi: 10.11591/ijict.v9i3.pp151-156.

[13] W. Yan, et al., "A hybrid genetic algorithm-interior point method for optimal reactive power flow," IEEE Trans. Power Syst., vol. 21, pp. 1163-1168, 2006, doi: 10.1109/TPWRS.2006.879262.

[14] K. Lenin, "Meleagris Gallopavo Algorithm for Solving Optimal Reactive Power Problem," International Journal of Applied Power Engineering (IJAPE), vol. 7, no. 2, pp. 99-110, 2018, doi: 10.11591/ijape.v7.i2.pp99-110.

[15] K. Lenin, "Power loss reduction by chaotic based predator-prey brain storm optimization algorithm," International Journal of Applied Power Engineering (IJAPE), vol. 9, no. 3, pp. 218-222, 2020, doi: 10.11591/ijape.v9.i3.pp218222.

[16] M. S. Ghayad, et al., "Reactive power control to enhance the VSC-HVDC system performance under faulty and normal conditions," International Journal of Applied Power Engineering (IJAPE), vol. 8, no. 2, pp. 145-158, 2019, doi: 10.11591/ijape.v8.i2.pp145-158.

[17] K. Lenin, "Solving optimal reactive power problem by enhanced fruit fly optimization algorithm and status of material algorithm," International Journal of Applied Power Engineering (IJAPE), vol. 9, no. 2, pp. 100-106, 2020, doi: 10.11591/ijape.v9.i2.pp100-106.

[18] K. Lenin, "Polar wolf optimization algorithm for solving optimal reactive power problem," International Journal of Applied Power Engineering (IJAPE), vol. 9, no. 2, pp. 107-112, 2020, doi: 10.11591/ijape.v9.i2.pp107-112.

[19] H. Yoshida, et al., "A particle swarm optimization for reactive power and voltage control considering voltage security assessment," IEEE Trans. Power Syst., vol. 15, pp. 1232-1239, 2000, doi: 10.1109/59.898095.

[20] J. Zhang, et al., "JADE: adaptive differential evolution with optionalexternal archive," IEEE Trans. Evolut. Comput., "vol. 13, pp. 945-958, 2009, doi: 10.1109/TEVC.2009.2014613.

[21] J. G. Vlachogiannis, et al., "A comparative study on particle swarm optimization for optimal steady-state performance of power systems," IEEE Trans. Power Syst., vol. 21 pp. 1718-1728, 2006, doi: 10.1109/TPWRS.2006.883687.

[22] M. Ghasemi, et al., "A new hybrid algorithm for optimal reactive power dispatch problem with discrete and continuous control variables," Appl Soft Comput., vol. 22, pp. 126-140, 2014, doi: 10.1016/j.asoc.2014.05.006.

[23] K. Lenin, "Power loss reduction by gryllidae optimization algorithm," International Journal of Informatics and Communication Technology (IJ-ICT), vol. 9, no. 3, pp. 179-184, 2020, doi: 10.11591/ijict.v9i3.pp179-184.

[24] M. Abdillah, et al., "Improvement of voltage profile for large scale power system using soft computing approach," TELKOMNIKA Telecommunication Computing Electronics and Control, vol. 18, no. 1, pp. 376-384, 2020, doi: 10.12928/telkomnika.v18i1.13379.

[25] Rajan, et al., "Optimal reactive power dispatch using hybrid Nelder-Mead simplex based firefly algorithm," Int J Elec Pwr Energy Syst, vol. 66, pp. 9-24, 2015, doi: 10.1016/j.ijepes.2014.10.041.

[26] R. Syahputra, I. Robandi, M. Ashari, "Reconfiguration of Distribution Network with Distributed Energy Resources Integration Using PSO Algorithm," TELKOMNIKA (Telecommunication, Computing, Electronics and Control), vol. 13, no. 3, pp. 759-766, 2015, doi: 10.12928/telkomnika.v13i3.1790.

[27] M. Damdar, et al., "Capacitor Placement Using Fuzzy And Particle Swarm Optimization Method For Maximum Annual Savings," ARPN Journal of Engineering and Applied Sciences, vol. 3, no. 3, pp. 25-30, June 2008. 
[28] R. C. Eberhart, et al., "Comparing inertia weights and constriction factors in particle swarm optimization," In Proceedings of the Congress on Evolutionary Computation, (CEC00), July 16-19, 2000, La Jolla, CA, USA, 2000, pp. 84-88, doi: 10.1109/CEC.2000.870279.

[29] F. Mijbas, et al., "Optimal Stabilizer PID Parameters Tuned by Chaotic Particle Swarm Optimization for Damping low frequency oscillations (LFO) for Single Machine Infinite Bus system (SMIB)," Journal of Electrical Engineering \& Technology, vol. 15, pp. 1577-1584,2020, doi: 10.1007/s42835-020-00442-5.

[30] D. Yang, et al., "On the efficiency of chaos optimization algorithms for global optimization," Chaos, Solitons \& Fractals., vol. 34, no. 4, pp. 1366-75, 2007, doi: 10.1016/j.chaos.2006.04.057.

[31] The IEEE 118-Bus Test System [online]. Available at: http://www.ee.washington.edu/research/pstca/pf118/pg_tca118bus.htm

[32] K. Mahadevan, et al., "Comprehensive learning particle swarm optimization for reactive power dispatch," Appl. Soft Comput, vol. 10, pp. 641-652, 2010, doi: 10.1016/j.asoc.2009.08.038.

\section{BIOGRAPHIES OF AUTHORS}

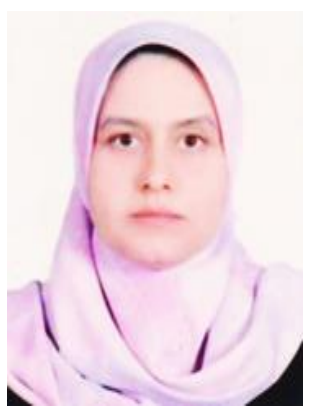

Shaima Hamdan Shri, received the four-year B.Sc. degreein Electrical Power Engineering Technics in 2013 from Electrical Engineering Technical College, Middle Technical University, Iraq. In 2018, she concluded a Master in Electrical Power Engineering Technics from Electrical Engineering Technical College, Middle Technical University, Iraq. Now an Assistant Lecturer at Department of Electrical Techniques, Technical Institute-Suwaira, Middle Technical University. Her main research interests include: Power System Stability and Optimization, Optimal Power Flow, Control of Renewable Energy Systems.

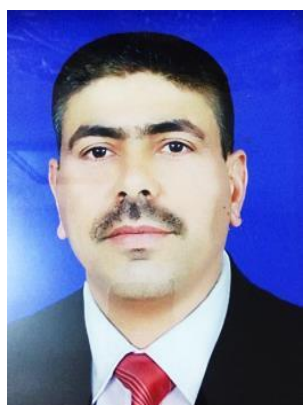

Ayad Fadhil Mijbas, received the five-year B.Sc. degree in Electrical Engineering Science in 1993 from Al-Technology University, Iraq. In 2004, he concluded a Master in Electrical Engineering Science/Control from Al-Technology University, Iraq. From 2006-2010 he has been as a head of Electrical debarment and lecturer in Foundation of Technical Education/Middle Technical University, Iraq. His main research interests include Electrical control system. 